\title{
Influence of processing on the phenolic compounds of feijoa pulp (Feijoa sellowiana)
}

\author{
Ana Carolina Leme Castelucci ${ }^{\mathrm{a}}$, Nataly Maria Viva de Toledo ${ }^{\mathrm{b}}$, Fernanda Francetto Juliano ${ }^{\mathrm{b}}$, \\ Paula Porrelli Moreira da Silva ${ }^{b^{*}}$ and Marta Helena Fillet Spoto ${ }^{\mathrm{b}}$
}

\begin{abstract}
${ }^{a}$ Center for Nuclear Energy in Agriculture, Centenário Avenue, 303, 13400-970, Piracicaba, SP, Brazil
bepartment of Agri-Food Industry, Food and Nutrition, "Luiz de Queiroz" College of Agriculture, University of São Paulo, Pádua Dias Avenue 11, Zip code 13418-900, Piracicaba, SP, Brazil

*Corresponding author: Paula Porrelli Moreira da Silva, Department of Agri-Food Industry, Food and Nutrition, "Luiz de Queiroz" College of Agriculture, University of São Paulo, Pádua Dias Avenue 11, Zip code 13418-900, Piracicaba, SP, Brazil. Tel: +55 19 34294150 ; E-mail: pporrelli@usp.br
\end{abstract}

DOI: $10.31665 /$ JFB.2020.11238

Received: March 20, 2020; Revised received \& accepted: March 31, 2020

Citation: Castelucci, A.C.L., de Toledo, N.M.V., Francetto Juliano, F., da Silva, P.P.M., and Fillet Spoto, M.H. (2020). Influence of processing on the phenolic compounds of feijoa pulp (Feijoa sellowiana). J. Food Bioact. 11: 66-74.

\begin{abstract}
The effect of processing on potential changes of antioxidant activity (DPPH and ABTS), total phenolic content (TPC) and total flavonoids (FLAV) of feijoa pulp during storage was investigated. In addition, possible modifications in the phenolic composition of the pulp. The pulp was subjected to refrigeration (control, $5^{\circ} \mathrm{C}$ ), pasteurization $(85$ ${ }^{\circ} \mathrm{C} / 5 \mathrm{~min}$ ) and irradiation (2.0 kGy). TPC, FLAV, DPPH and ABTS were measured during 28 days, whereas the identification and quantification of phenolic compounds were conducted after processing. The results were submitted to principal component analysis (SAS 9.4). Pasteurization preserved TPC, DPPH and ABTS for 21 days, while in the irradiated samples and control, the values were decreased and FLAV were maintained at high levels. The profile of phenolic compounds was different for each sample with six compounds being identified.
\end{abstract}

Keywords: Antioxidants; Pasteurization; Irradiation; Phenolic Compounds; Principal Component Analysis; Brazilian native fruits.

\section{Introduction}

Brazil has a wide variety of native fruits with unique and attractive flavors for commercialization. Furthermore, these fruits are often important sources of bioactive compounds, such as polyphenols, which comprise a large group of molecules whose regular consumption has been associated with anti-inflammatory, antioxidant, and cardioprotective effects as well as immuno-stimulating activity (Weston, 2010; Alov et al., 2015; Szymanowska and Baraniak, 2019).

Considering the present perspectives, better use of native fruits by the food industry may be a way to provide innovative and healthier products. Although some native fruits present an interesting composition, many are still inadequately known and are not explored by the commercial market as is the case for feijoa (Feijoa sellowiana), a fruit that belongs to the Myrtaceae family, and contains high amounts of vitamin C, flavonoids (quercetin glycosides, procyanidins and catechins) and phenolic acids (Weston, 2010; Karami et al., 2013; Mosbah et al., 2019).

Due to its high perishability, the processing of feijoa for commercialization as frozen products or refrigerated pulp is stimulated as a way to extend its shelf life and add value it (Karwowski et al., 2013). However, attention must be paid to the processing method chosen, in order to reduce possible losses of nutritional value and bioactive compounds.

In this context, besides the conventional conservation methods such as pasteurization, refrigeration, and freezing, other technologies have been employed to increase the shelf life of products, such as irradiation, because it is a non-thermal technology which contributes to the conservation, distribution and marketing of the pulp, by inactivating pathogenic and spoilage microorganisms (Aneja et al., 2014).

Although some studies have demonstrated the impact of the processing on the bioactive compounds of feijoa pulp (Buratto et 
al., 2019; Castelucci et al. 2020), to the best of our knowledge, there has been no report focusing on the fresh feijoa pulp and its shelf life using irradiation compared to other conventional methods. Considering the potential use of this fruit for manufacturing new foodstuffs, further studies must be carried out to indicate the advantages of using different processing methods in order to avoid the loss of functional compounds. Therefore, this study aimed to verify whether different processing methods (refrigeration, pasteurization and irradiation) had an effect on changes of the antioxidant activity, total phenolic content and total flavonoids of feijoa pulp during storage, both quantitatively and qualitatively.

\section{Material and methods}

\subsection{Raw material and pulp processing}

The feijoa fruits were obtained from a producer in Paraibuna (São Paulo, Brazil). The fruits were harvested in 2012 and stored at -18 ${ }^{\circ} \mathrm{C}$ for one month, until processing. For pulping, the fruits passed by a selection for high quality, and were washed and sanitized with active chlorine solution $\left(200 \mathrm{mg} \mathrm{L}^{-1}\right)$ for $15 \mathrm{~min}$. The material was crushed and homogenized in an industrial stainless-steel blender $(2: 1, \mathrm{w} / \mathrm{v})$ with mineral water for $3 \mathrm{~min}$ at room temperature $(25$ $\left.{ }^{\circ} \mathrm{C}\right)$. The pulps were separated into three portions for treatments via refrigeration (control), pasteurization and irradiation.

The control treatment consisted of storing the pulp at $5{ }^{\circ} \mathrm{C}$ (nonirradiated and non-pasteurized pulp). For the pasteurization treatment, the pulps were treated in an open pan $(36 \mathrm{~cm})$ at $85^{\circ} \mathrm{C}$ for $5 \mathrm{~min}$, and rapidly cooled down after thermal treatment in an ice bath, and packed in polyethylene bags $(10 \times 15 \mathrm{~cm})$ with $100 \mathrm{~mL}$ of pulp that were stored under refrigeration $\left(5^{\circ} \mathrm{C}\right)$. For irradiation treatment, the pulps were packed in polyethylene bags $(100 \mathrm{~mL})$ and stored at $-18{ }^{\circ} \mathrm{C}$ in a commercial freezer until the irradiation process. According to previous studies (Silva et al., 2018), irradiation doses above $2.5 \mathrm{kGy}$ have not shown satisfactory results for fruit pulps. Thus, the lots were irradiated in the radiator of the Institute of Energy and Nuclear Research (IPEN, São Paulo, Brazil), using a commercial source of cobalt- 60 with $2.0 \mathrm{kGy}$ and subsequently were stored at $5{ }^{\circ} \mathrm{C}$. The dose was $2.30 \mathrm{kGy} \mathrm{hour}^{-1}$, and the boxes were positioned at $30 \mathrm{~cm}$ from the source for $2 \mathrm{~h}$.

The samples (three repetitions) were stored under refrigeration $\left(5^{\circ} \mathrm{C}\right.$ ) for 28 days (in the dark, to avoid the oxidation of the phenolic compounds). The experimental design was randomized factorial, composed of three treatments (control, pasteurization and irradiation) and five periods of analysis $(1,7,14,21$ and 28 days after processing).

\subsection{Phenolic extract}

For the preparation of the phenolic extract, $10 \mathrm{~g}$ of feijoa pulp were vortexed $(1 \mathrm{~min})$ with $20 \mathrm{~mL}$ of ethanol/water $(80: 20, \mathrm{v} / \mathrm{v})$ and allowed to stand for $50 \mathrm{~min}$ at room temperature $\left(25^{\circ} \mathrm{C}\right)$. The extract was centrifuged at $8,000 \mathrm{~g}$ for $15 \mathrm{~min}$ at $4{ }^{\circ} \mathrm{C}$ in a refrigerated Eppendorf-R-5810 centrifuge (Hamburg, Germany) and the supernatant (ethanolic extract) was used for the subsequent analyses.

\subsection{Total phenolic compounds}

Folin-Ciocalteau method (Singleton, 1965) was employed to measure the total phenolic compounds. The absorbance was read at 765 $\mathrm{nm}$ in a UV/VIS Femto-432C spectrophotometer (São Paulo, Brazil) and the results were expressed as $\mathrm{mg}$ of gallic acid equivalents (GAE) per $g$ of pulp on the wet basis.

\subsection{Total flavonoids}

Total flavonoids were determined according to Park et al. (1995) and the absorbance was read at $415 \mathrm{~nm}$ using a UV/VIS Femto$432 \mathrm{C}$ spectrophotometer. The results were expressed as $\mathrm{mg}$ of quercetin equivalents per $100 \mathrm{~g}$ of pulp on the wet basis.

\subsection{Antioxidant activity}

The antioxidant capacity was evaluated by DPPH and ABTS analyses. The DPPH assays were conducted according to BrandWilliams et al. (1995). The solutions were mixed and the reduction of the DPPH radical was measured by reading the absorbance at $515 \mathrm{~nm}$ in a UV/VIS Femto-432C spectrophotometer after $50 \mathrm{~min}$ of reaction. Results were expressed in $\mu \mathrm{M}$ of trolox equivalents per $\mathrm{g}$ of pulp on the wet basis. For the ABTS assays, the methodology described by Rufino et al. (2007) was used. The reduction of the $\mathrm{ABTS}^{*+}$ was measured at $734 \mathrm{~nm}$ using a UV/VIS Femto-432C spectrophotometer after 6 min of reaction. The results were expressed in $\mu \mathrm{M}$ of trolox equivalents per $\mathrm{g}$ of pulp on the wet basis.

\subsection{Identification and quantification of the phenolic compounds in feijoa pulp}

Thirteen phenolic compounds (1,3-dicaffeoylquinic acid, 1,5-dicaffeoylquinic acid, caffeic acid, $p$-coumaric acid, chlorogenic acid, ellagic acid, ferulic acid, gallic acid, quinic acid, shikimic acid, kaempferol, quercetin and rutin) were identified and quantified in samples of feijoa pulp by UHPLC-MS.

For this analysis, the feijoa pulp was primarily lyophilized (Apparatus Inc., New York, NY, USA) and employed in the extraction of the phenolic compounds by the use of a FastPrep ${ }^{\circledR}-24$ homogenizer. In this, $10 \mathrm{mg}$ of the material were added to a tube with 1.5 $\mathrm{mL}$ of water/methanol $(1: 1, \mathrm{v} / \mathrm{v})$ and porcelain pearls. The samples were agitated at a speed of $5.0 \mathrm{~ms}^{-1}$ for $120 \mathrm{~s}$ and then filtered.

The identification and quantification of the phenolic compounds were performed using ultra-high-performance liquid chromatography (UHPLC) Accela 1250 pump, coupled to a Thermo Scientific high-resolution mass spectrometer, model LTQ Orbitrap Velos with electrospray ionization (ESI) operating in the negative mode. The samples were injected $(10 \mu \mathrm{L})$ by an autosampler Accela Open, and a (C18) Phenomenex Kinetex PFP column (150 mm x $3.00 \mathrm{~mm} \times 2.6 \mu \mathrm{m}$ ) was employed, with the flow of the mobile phase of $500 \mu \mathrm{L} \mathrm{min}^{-1}$. The mobile phase used consisted of a gradient of water $/ 0.1 \%$ formic acid (solvent $\mathrm{A}$ ) and methanol $/ 0.1 \%$ formic acid (solvent B), which was eluted in a linear gradient: from 5 to $80 \%(\mathrm{v} / \mathrm{v})$ of B for $5 \mathrm{~min}$; from 80 to $100 \%(\mathrm{v} / \mathrm{v})$ of B for 5 min; 3 min with $100 \%$ of $\mathrm{B}$; from $100 \%$ to $5 \%(\mathrm{v} / \mathrm{v})$ of $\mathrm{B}$ for 4 min, and 3 min with B at $5 \%$. For the quantification of compounds, the calibration curve was constructed using authentic standards (Sigma-Aldrich, St. Louis, MO, USA). The results were expressed in $\mu \mathrm{g} \mathrm{g}^{-1}$ of pulp on the wet basis.

\subsection{Statistical analysis}

The results obtained in the evaluation of the phenolic compounds 
Table 1. Antioxidant activity, phenolic compounds and flavonoids of feijoa pulp subjected to refrigeration (control), irradiation (2.0 kGy) and pasteurization $\left(85^{\circ} \mathrm{C} / 5 \mathrm{~min}\right.$ ) during 28 days of refrigerated storage (mean \pm standard deviation, $n=3$ )

\begin{tabular}{|c|c|c|c|c|c|}
\hline \multirow[b]{2}{*}{ Treatments } & \multicolumn{5}{|c|}{ Storage period (days) } \\
\hline & 1 & 7 & 14 & 21 & 28 \\
\hline \multicolumn{6}{|c|}{ DPPH radical scavenging activity ( $\mu \mathrm{M}$ of trolox equivalents $\mathrm{g}^{-1}$ of pulp) } \\
\hline Control & $53.74 \pm 8.95$ & $39.20 \pm 3.78$ & $20.53 \pm 2.69$ & $25.36 \pm 2.77$ & $22.97 \pm 2.10$ \\
\hline Irradiation & $48.92 \pm 2.06$ & $46.06 \pm 4.30$ & $33.89 \pm 1.31$ & $21.41 \pm 3.42$ & $26.57 \pm 0.57$ \\
\hline Pasteurization & $49.61 \pm 0.69$ & $37.74 \pm 4.09$ & $41.84 \pm 6.70$ & $39.95 \pm 7.05$ & $49.60 \pm 0.58$ \\
\hline \multicolumn{6}{|c|}{ ABTS radical scavenging assay ( $\mu \mathrm{M}$ of trolox equivalents $\mathrm{g}^{-1}$ of pulp) } \\
\hline Control & $42.87 \pm 6.11$ & $32.89 \pm 4.38$ & $34.24 \pm 6.96$ & $26.98 \pm 1.20$ & $28.98 \pm 2.61$ \\
\hline Irradiation & $39.34 \pm 5.25$ & $42.21 \pm 2.05$ & $47.07 \pm 0.80$ & $23.72 \pm 2.75$ & $31.47 \pm 0.30$ \\
\hline Pasteurization & $41.63 \pm 1.72$ & $55.31 \pm 5.39$ & $59.26 \pm 6.05$ & $58.15 \pm 0.59$ & $59.40 \pm 0.37$ \\
\hline \multicolumn{6}{|c|}{ Total phenolic compounds (mg of gallic acid equivalents $\mathrm{g}^{-1}$ of pulp) } \\
\hline Control & $10.21 \pm 0.75$ & $6.01 \pm 0.84$ & $5.09 \pm 0.91$ & $5.09 \pm 0.91$ & $4.98 \pm 0.61$ \\
\hline Irradiation & $9.75 \pm 0.78$ & $7.77 \pm 0.28$ & $6.54 \pm 0.14$ & $6.54 \pm 0.14$ & $4.23 \pm 0.84$ \\
\hline Pasteurization & $12.64 \pm 0.47$ & $10.35 \pm 1.21$ & $12.42 \pm 1.10$ & $12.42 \pm 1.10$ & $6.20 \pm 0.07$ \\
\hline \multicolumn{6}{|c|}{ Total flavonoids (mg of quercetin equivalents $100 \mathrm{~g}^{-1}$ of pulp) } \\
\hline Control & $68.40 \pm 9.39$ & $42.50 \pm 1.67$ & $40.25 \pm 2.24$ & $47.99 \pm 5.34$ & $21.01 \pm 0.47$ \\
\hline Irradiation & $53.82 \pm 4.74$ & $44.33 \pm 7.30$ & $40.46 \pm 2.08$ & $31.51 \pm 3.16$ & $18.65 \pm 5.99$ \\
\hline Pasteurization & $58.48 \pm 7.82$ & $30.89 \pm 4.36$ & $29.17 \pm 3.45$ & $26.74 \pm 2.12$ & $13.56 \pm 2.70$ \\
\hline
\end{tabular}

during the storage period and in the analysis of identification and quantification of phenolic compounds were subjected to the Principal Component Analysis (PCA), based on the Correlation Matrix. For this, the statistics program SAS 9.4 was employed.

\section{Results}

\subsection{Total phenolic compounds, flavonoids and antioxidant ac- tivity of the feijoa pulp during storage}

The PCA extracted two principal components from the total dataset (Table 1), explaining $88.45 \%$ of the variance. The first principal component (Component 1) explained $58.81 \%$ of the statistical variance and was positively correlated with the variables antioxidant activity by the DPPH method and total phenolic compounds (TPC) (Figure 1). The second principal component (Component 2) explained $29.64 \%$ of the statistical variance and was positively correlated with the variable flavonoids (FLAV). The variable antioxidant activity by the ABTS method was correlated with the third principal component, which is not present in the cloud of observations and variables because it corresponded with only $11.55 \%$ of the total variance.

On the first day of storage, the control feijoa pulp (refrigerated) presented higher values of FLAV, TPC and DPPH. On the other hand, after seven days of storage, a reduction in the values of flavonoids was observed, with the results of antioxidant activity (DPPH) and TPC staying close to those of the general mean among the observations. After the $14^{\text {th }}$ day of storage, the samples of the control treatment presented a similar profile until the end of the analyses. An interesting fact for this treatment is that the content of flavonoids of the samples stored for 21 days remained above those verified in the pasteurized and irradiated samples.

The pasteurized samples, on the other hand, when compared to the control treatment, presented higher values of DPPH and TPC, and lower flavonoid content with values remained similar during the entire storage period. Although the pasteurized samples demonstrated a flavonoid content below the general mean of the observations (between 7 and 28 days of storage), the pasteurization applied to feijoa pulp can be considered an advantageous technique, since it is less expensive than irradiation, for instance, and maintained the contents of TPC and antioxidant activity (DPPH and ABTS) at satisfactory levels.

When compared to the other treatments, the irradiated pulps (2.0 kGy) presented the lowest amount of FLAV, DPPH and TPC on the first day of storage. During storage, a decrease in the above values was noticed in each period. It is worth noting that despite the decreases observed after 28 days of storage, the values of TPC and of DPPH in the irradiated samples were similar to those of the control samples.

Furthermore, among the variables presented in Figure 1, a high positive correlation existed between TPC and DPPH, since they are positioned in an angle close to zero degree.

\subsection{Identification and quantification of the phenolic compounds in feijoa pulp}

Among the 13 compounds analyzed, six phenolic compounds were identified and quantified in the feijoa pulp subjected to different treatments (Figure 2, Table 2), each observation (control, pasteurized and irradiated) evidencing a specific profile of phenolic compounds.

The PCA extracted two principal components from the total dataset (Table 2), explaining $100 \%$ of the variance. The first princi- 


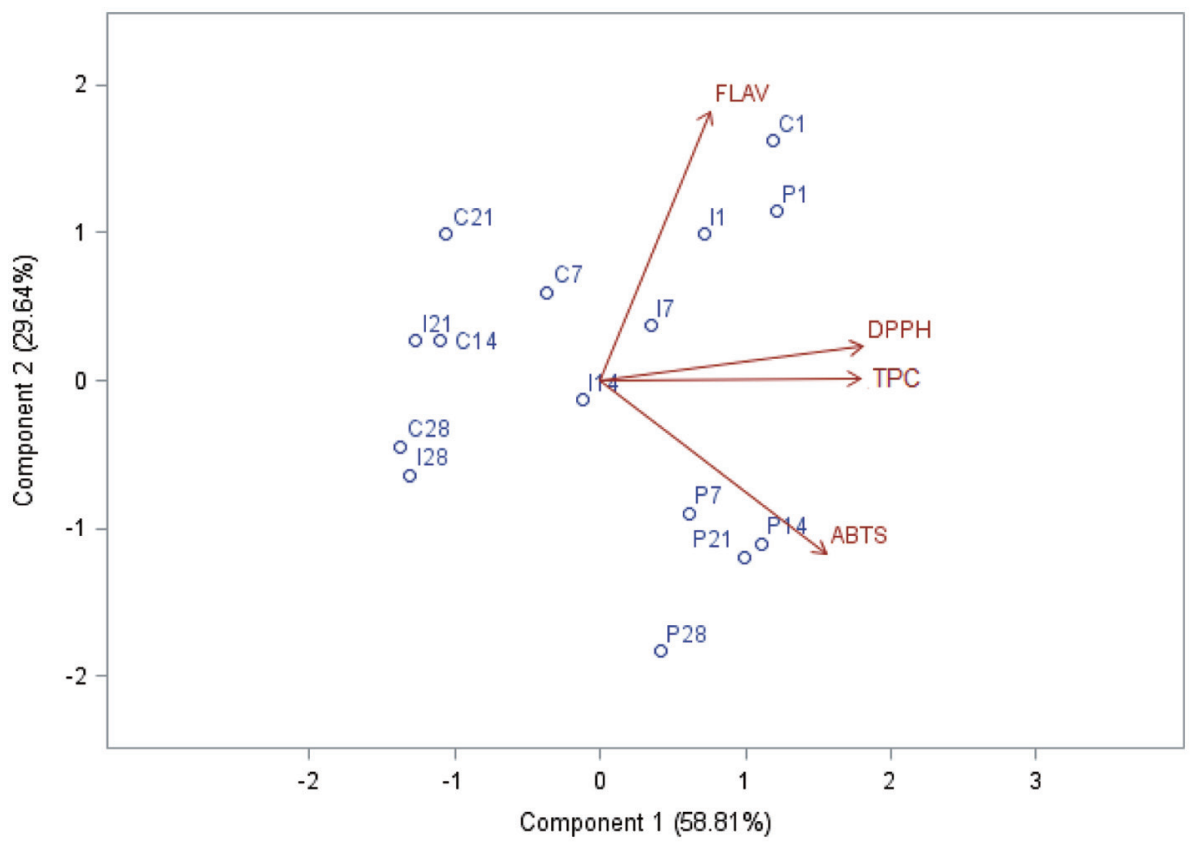

Figure 1. Distribution of the cloud of variables and observations, obtained in the Principal Component Analysis (PCA) from the results of antioxidant activity, phenolic compounds and flavonoids of the feijoa pulp submitted to refrigeration (control), irradiation $(2.0 \mathrm{kGy})$ and pasteurization $\left(85^{\circ} \mathrm{C} / 5 \mathrm{~min}\right)$ during storage $\left(5^{\circ} \mathrm{C}, 28\right.$ days). Variables: FLAV = total flavonoids (mg of quercetin equivalents $100 \mathrm{~g}^{-1}$ of pulp); DPPH = DPPH radical scavenging activity ( $\mu \mathrm{M}$ of trolox equivalents $\mathrm{g}^{-1}$ of pulp); TPC = Total phenolic compounds ( $\mathrm{mg}$ of gallic acid equivalents $\mathrm{g}^{-1}$ of pulp); ABTS = ABTS radical scavenging assay $(\mu \mathrm{M}$ of trolox equivalents $\mathrm{g}^{-1}$ of pulp). Observations: $\mathrm{C} 1=$ control stored for 1 day; $\mathrm{C} 7=$ control stored for 7 days; $\mathrm{C} 14=$ control stored for 14 days; $\mathrm{C} 21=$ control stored for 21 days; $\mathrm{C} 28$ = control stored for 28 days; 11 = irradiated ( $2.0 \mathrm{kGy}$ ) stored for 1 day; $\mathrm{C} 7$ = irradiated (2.0 kGy) stored for 7 days; $\mathrm{C} 14=$ irradiated (2.0 kGy) stored for 14 days; C21 = irradiated (2.0 kGy) stored for 21 days; C28 = irradiated (2.0 kGy) stored for 28 days.

pal component (Component 1) explained $69.52 \%$ of the statistical variance and was positively correlated with the compounds ellagic acid, quercetin and caffeic acid; and negatively correlated with quinic acid (Figure 2). The second principal component (Component 2) explained $30.48 \%$ of the statistical variance and was positively correlated with the compound shikimic acid, and negatively with gallic acid.

The control feijoa pulp (refrigerated) was characterized by a higher amount of gallic acid and lower contents of quinic acid, shikimic acid and caffeic acid. Meanwhile, intermediate values were found for ellagic acid and quercetin (Figure 2). Conversely, the pasteurized pulp presented higher values for caffeic acid, ellagic acid and quercetin. In this sample, lower values were verified for gallic acid, quinic acid and shikimic acid. On the other hand, the irradiated sample $(2.0 \mathrm{kGy})$ presented higher values for quinic acid and shikimic acid and lower values for ellagic acid and quercetin.

Regarding the correlations among the compounds, a high positive correlation existed between ellagic acid and quercetin (positioned with angle close to $0^{\circ}$ ). On the contrary, gallic acid and caffeic acid showed a high negative correlation since the variables are positioned with angle close to $180^{\circ}$ from each other.

\section{Discussion}

\subsection{Total phenolics, flavonoids and antioxidant activity of feijoa pulp during storage}

The search for strategies for the preservation of phenolic compounds in fruit-based products is mandatory for the functionality and quality of the end product. During the storage period, it was observed that the contents of total phenolic compounds (TPC), total flavonoids (FLAV) and antioxidant activity (DPPH) for the control treatment decreased, which precludes the storage of the product for long periods.

According to Galani et al. (2017), the storage of fruits and vegetables at $4{ }^{\circ} \mathrm{C}$ for 15 days significantly decreased their TPC content, drastically affecting the results of antioxidant activity, especially by the DPPH method, which is coherent with that observed in the present study, given the high correlation existing between these two parameters (Figure 1). Furthermore, many factors can influence the antioxidant activity of fruit pulps, including colloidal properties of the substrates, the conditions and oxidation stages, the formation and stability of the radical, as well as the possible location of antioxidants and their stability at different processing stages in food (Rockenbach et al., 2008).

It is worth noting that although both the DPPH and ABTS methods are considered indirect methods for determination of antioxidant activity; these assays present distinct forms of analysis regarding the solubility of the compounds present in the samples. In the ABTS method, both lipophilic and hydrophilic compounds are identified, whereas by DPPH there is a higher sensitivity for the hydrophilic compounds (Dastmalchi et al., 2011). Therefore, since the DPPH method is represented by Component 1, it is possible to affirm that there was a dominance of hydrophilic compounds (e.g. phenolic acids, phenylpropanoids, flavonoids and quinones) (Guiné and Barroca, 2014) related to the antioxidant activity in the samples of refrigerated feijoa pulp.

In general, the values for antioxidant activities by the DPPH method in feijoa pulp, regardless of the treatment used, were similar to the values described for acerola pulp $(68.0 \mu \mathrm{mol}$ of trolox 


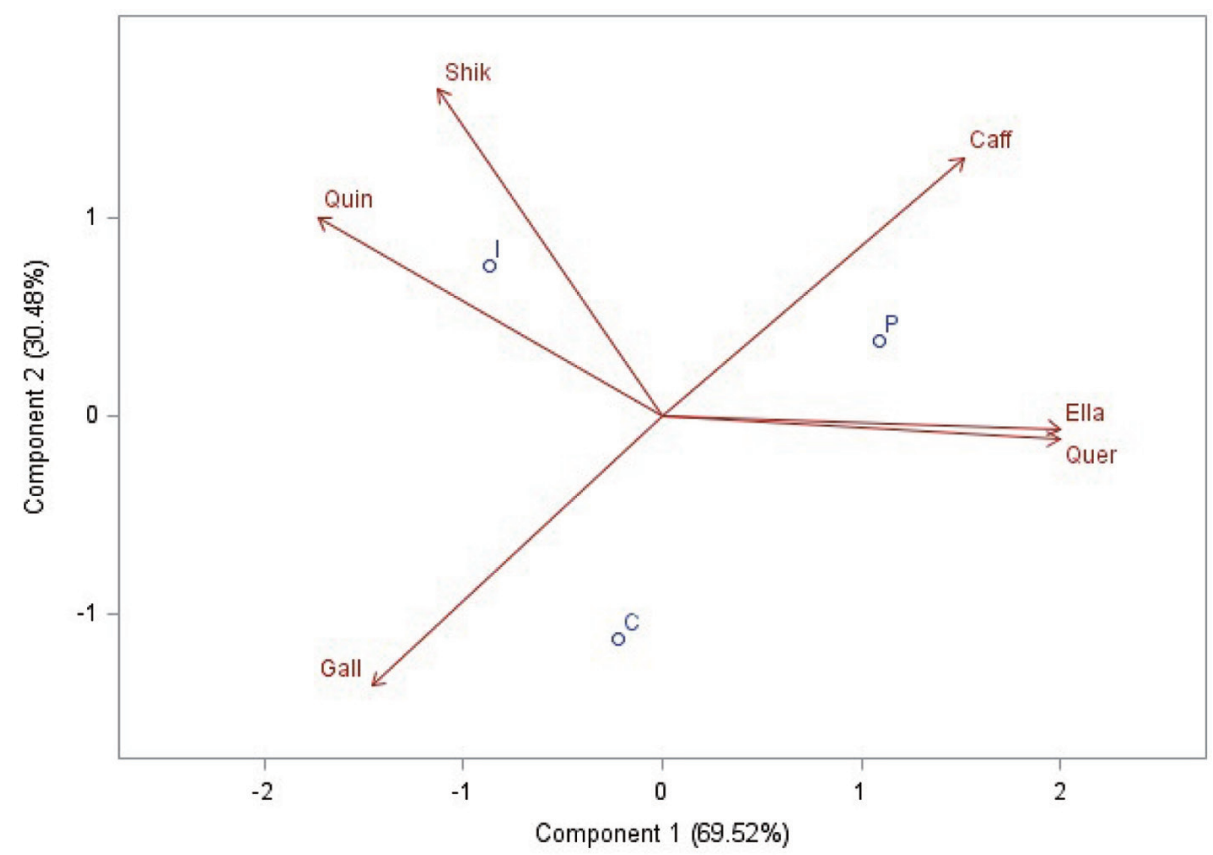

Figure 2. Distribution of the cloud of variables and observations, obtained in the Principal Component Analysis (PCA) from the phenolic compounds identified and quantified $\left(\mu \mathrm{g} \mathrm{g}^{-1}\right)$ in feijoa pulp subjected to refrigeration (control), irradiation ( $2.0 \mathrm{kGy}$ ) and pasteurization $\left(85^{\circ} \mathrm{C} / 5 \mathrm{~min}\right)$. Variables: Shik = Shikimic acid; Caff = Caffeic acid; Ella = Ellagic acid; Quer = Quercetin; Gall = Gallic acid; Quin = Quinic acid. Observations: $\mathrm{C}=$ refrigerated feijoa pulp (control); I = irradiated feijoa pulp (2.0 kGy); $\mathrm{P}=$ pasteurized feijoa pulp $\left(85^{\circ} \mathrm{C} / 5 \mathrm{~min}\right)$.

equivalents $\mathrm{g}^{-1}$ ) (Kuskoski et al., 2005), a fruit which presents considerable antioxidant activity. The authors also found $7.4 \mu \mathrm{mol}$ of trolox equivalents $\mathrm{g}^{-1}$ in guava pulp, a fruit belonging to the same family of feijoa.

Regarding the behavior of the samples in relation to the other processing strategies studied, pasteurization was observed to be the most promising method in terms of the preservation of the total phenolic compounds and the antioxidant activity for feijoa pulp, with the pasteurized samples presenting a lower loss of the total phenolic compounds $(1.74 \%)$, when compared to the control $(50.14 \%)$ and irradiated $(32.92 \%)$ samples after 21 days of storage. It is known that pasteurization is a thermal process capable of inactivating enzymes and reducing microbial load, which may have contributed to prevent the oxidation of phenolic compounds in the samples subjected to this treatment (Kaur and Kapoor, 2001).

Mena et al. (2013) reported similar results for juice samples that

Table 2. Phenolic compounds identified and quantified ( $\mu \mathrm{g} \mathrm{g}^{-1}$ of pulp) in feijoa pulp subjected to refrigeration (control), irradiation ( $2 \mathrm{kGy}$ ) and pasteurization $\left(85^{\circ} \mathrm{C} / 5 \mathrm{~min}\right)$

\begin{tabular}{llll}
\hline Phenolic compound & Control & Irradiation & Pasteurization \\
\hline 1,3-Dicaffeoylquinic acid & LD & LD & LD \\
1,5-Dicaffeoylquinic acid & LD & LD & LD \\
Caffeic acid & $14.9 \pm 0.001$ & $19.0 \pm 0.001$ & $25.9 \pm 0.001$ \\
Chlorogenic acid & LQ & LQ & LQ \\
p-Coumaric acid & LQ & LQ & LQ \\
Ellagic acid & $290.0 \pm 0.004$ & $237.0 \pm 0.004$ & $383.0 \pm 0.003$ \\
Ferulic acid & LD & LD & LD \\
Gallic acid & $80.1 \pm 0.004$ & $77.2 \pm 0.0036$ & $73.0 \pm 0.003$ \\
Quinic acid & $217.0 \pm 0.007$ & $269.0 \pm 0.007$ & $204.0 \pm 0.006$ \\
Shikimic acid & $21.9 \pm 0.0001$ & $27.2 \pm 0.001$ & $23.3 \pm 0.0001$ \\
Kaempferol & LQ & LQ & LQ \\
Quercetin & $6.24 \pm 0.0033$ & LQ & $16.1 \pm 0.003$ \\
Rutin & LQ & LQ & LQ \\
\hline
\end{tabular}

LQ (limit of quantification) $=6.0910^{-3} \mathrm{mg} \mathrm{g}^{-1}$ of extract; LD (limit of detection $)=3.1010^{-6} \mathrm{mg} \mathrm{g}^{-1}$ of extract. 
showed higher antioxidant activity values following processing under mild temperature pasteurization (MTP) and high temperature pasteurization (HTP) conditions compared to the samples subjected to low-temperature pasteurization (LTP) that did not suffer any thermal treatment.

Although there were some variations in the results of antioxidant activity (DPPH), it was observed that the sample of pasteurized pulp tended to remain stable during the storage period (Figure 1, Table 1). Small positive fluctuations were also observed for the TPC content during the $14^{\text {th }}$ and $21^{\text {st }}$ days of storage of the pasteurized feijoa pulp, similar to that reported by Castro-Lopez et al. (2016) when analyzing the TPC content of pasteurized fruit beverages $\left(95^{\circ} \mathrm{C}, 15 \mathrm{~s}\right)$ after the 12 days of storage.

Studies have demonstrated that thermal food processing treatments can present positive effects (Guiné and Barroca, 2014), such as TCP content and antioxidant activity (DPPH and ABTS) in the pasteurized feijoa pulps. However, some detrimental effects such as lower FLAV contents were observed for the pasteurized pulps compared to the control and irradiated samples.

Flavonoids are among the major metabolites found throughout the plant kingdom, especially in fruits and vegetables. Their consumption has grown in the past years, given their numerous health benefits and because these compounds can also be used as functional compounds and natural food ingredients (Ahmed and Eun, 2018).

Studies have demonstrated that the use of thermal treatment for the preservation of vegetable products may cause degradation of total flavonoids. Igual et al. (2011) evaluated the effect of conventional pasteurization (water bath at $80{ }^{\circ} \mathrm{C} / 11$ seconds) on the flavonoid content in grapefruit juice, and concluded that heating caused a decrease in FLAV content. According to Fuleki and Ricardo-da-Silva (2003), pasteurization combined with cold pressing increased the content of some flavonoids (e.g. catechins and procyanidins) in grape juice but when the samples were subjected to further thermal treatment (hot pressing), there was a decrease in the concentration of these compounds. Variations for the total flavonoids after the use of pasteurization $\left(70^{\circ} \mathrm{C}\right.$ for $\left.1 \mathrm{~h}\right)$ were also identified by Medina-Meza and Barbosa-Canovas (2015) in the analysis of grape and plum peels. Thus, in order to prevent fluctuations in the phenolic compounds (e.g. flavonoids) in foodstuffs, other non-thermal methods, such as irradiation, are gaining more popularity because these approaches allow the retention of the nutritional value in various functional foods in addition to their role in food preservation (Ahmed and Eun, 2018; Khan et al., 2018).

For this study, however, it was verified that the feijoa pulp subjected to gamma radiation $(2.0 \mathrm{kGy})$ presented decreases in phenolic compounds and antioxidant activity (DPPH and ABTS) during the storage period. This result is supported by studies on the effects of the gamma radiation in juçara pulp subjected to doses between 2.5 and $10 \mathrm{kGy}$ (Silva et al., 2018); in oranges, between 0.5 and $2.0 \mathrm{kGy}$ (Jo et al., 2019); in strawberries, between 1.0 and $10 \mathrm{kGy}$ (Breitfellner et al., 2002); in kale juice, between 0.3 and $5.0 \mathrm{kGy}$ (Song et al., 2006) and in sour cherry juice, between 0.5 and 6.0 kGy (Arjeh et al., 2015). The decrease in the antioxidant activity and the phenolic compounds may be related to the indirect action of the gamma radiation on the organic compounds present in fruits or vegetables. One of these effects is water radiolysis, which promotes the formation of hydroxyl radicals, hydrated electrons and hydrogen atoms, which may break the glycosidic bonds of phenolic compounds (Breitfellner et al., 2002; Lee et al., 2009).

In contrast, the irradiated samples presented flavonoid contents above those observed in the pasteurized samples, in which at 7 and 14 days of storage, the irradiated had approximately 44 and 39\% more of such compounds, respectively (Table 1). Pongamia pin- nata leaves subjected to gamma radiation (100-600 Gy) also evidenced the rise in the flavonoid content after treatment (Wani et al., 2019). Irradiated sesame seeds (3, 6, 9 and $12 \mathrm{kGy})$, likewise, preserved a high flavonoid content during 12 months of storage (Hajar et al., 2019). Studies indicate that radiations, such as gamma or UV radiation, can stimulate phenylalanine ammonia lyase (PAL) biosynthesis, which, in turn, increases flavonoid production in the samples (Hadwiger and Schwochau, 1971; Oufedjikh et al., 2000).

\subsection{Identification and quantification of phenolic compounds in feijoa pulp}

Plant foods containing high amounts of phenolic compounds and antioxidant potential can be used in nutraceuticals and functional foods for health promotion and disease risk reduction (Shahidi, 2005). The identification and quantification of the phenolic compounds in feijoa pulp subjected to different processings (refrigeration, irradiation or pasteurization) were performed on the first day of storage. The results indicated that the contents of flavonoids and total phenolic compounds were similar among the samples, but it was observed that the use of different methods resulted in the dominance of distinct phenolic compounds in the end product.

According to the literature, the fruit of feijoa may contain significant amounts of catechins, leucoanthocyanins, proanthocyanidins, naphthoquinones, syringic and trans-cinnamic acids in its flesh, whereas ferulic and $o$-coumaric acids and these occur most commonly in the peels (Romero Rodriguez et al., 1992; Ielpo et al., 2000; Tuncel and Yilmaz, 2015). Considering the results obtained in the present study, among the compounds identified in feijoa pulp, only quercetin is a flavonols which is commonly found in large amounts in onions, broccoli, apples and berries (Aherne and O'Brien, 2002; Arya et al., 2014). Researches have indicated that quercetin exerts a protective effect in the human organism against a series of diseases (Yokoyama et al., 2009; Yousef et al., 2010). In the present study, quercetin was found in the highest amount in the sample of pasteurized pulp $\left(16.1 \mu \mathrm{g} \mathrm{g}^{-1}\right)$, and it was not identified in the irradiated samples. Nonetheless, it is worth highlighting that, given the elevated content of total flavonoids (FLAV) in the irradiated feijoa pulp, it is believed that other compounds belonging to the class of the flavonoids, that were not included in this study, might be present in the irradiated samples, justifying the result obtained in the shelf life study.

Regarding non-flavonoids, the most important compounds in the diet are phenolic acids, which include gallic and ellagic acids (phenolic acids with chemical structure C6-C2-C6), caffeic and ferulic acids (hydroxycinnamates of structure C6-C3) and resveratrol (stilbenes C6-C2-C6) (Crozier, 2003). Among these compounds, the first three were identified in relevant amounts in the pulp of feijoa.

In the pasteurized pulp, caffeic acid was present in the highest amount $\left(25.9 \mu \mathrm{g} \mathrm{g}^{-1}\right)$ in comparison with the other treatments. A similar behavior was observed by Bhattacherjee et al. (2011) for pasteurized aonla juice at $90{ }^{\circ} \mathrm{C}$ during the first days of storage. On the other hand, Gil-Izquierdo et al. (2002) observed its degradation after thermal treatment (pasteurization at $95{ }^{\circ} \mathrm{C}$ ) of orange juice. Given its powerful antioxidant activity, caffeic acid has the potential for use in medications and cosmetics. Its consumption has been related to the increase in collagen production and prevention of premature aging, antimicrobial activity, in addition to possible effects in the treatment of dermal diseases (Magnani et al., 2014).

Similarly, it was observed that pasteurization contributed to the rise in ellagic acid content $\left(383.0 \mu \mathrm{g} \mathrm{g}^{-1}\right)$ in feijoa pulp, which is in accordance with that recommended by Mena et al. (2013) in 
a study with pasteurized pomegranate juices $\left(80^{\circ} \mathrm{C}\right.$ or $95^{\circ} \mathrm{C}$ for $30 \mathrm{~s}$ ) and by Marszałek et al. (2015) in the analysis of pasteurized strawberry puree $\left(90^{\circ} \mathrm{C}\right.$ for $\left.15 \mathrm{~min}\right)$. Ellagic acid is known as the product formed upon hydrolysis of ellagitannins, a compound commonly found in plant species of the Myrtaceae family (Aoyama et al., 2018) as is the case for feijoa. Heat treatment can contribute to an increase in the level of ellagic acid due to its release from ellagitannins (Zafrilla et al., 2001). Thus, it can be observed that thermal treatment can influence the release of certain antioxidant compounds from fruit tissues, increasing their presence according to the binomial time and temperature employed.

The samples of feijoa pulp subjected to irradiation evidenced higher values of quinic acid $\left(269.0 \mu \mathrm{g} \mathrm{g}^{-1}\right)$ and of shikimic acid $\left(27.2 \mu \mathrm{g} \mathrm{g}^{-1}\right)$, indicating that the treatment did not degrade them. The first is a polyphenol that occurs naturally in fruits, coffee, cocoa beans and wine, and it can also be synthesized via the hydrolysis of chlorogenic acid, whose antioxidant activity is higher than that of certain synthetic antioxidants, such as butylated hydroxytoluene (BHT) (Hung et al., 2006; Cinkilic et al., 2013). Similar to this study, Nagy et al. (2011), using a Cobalt-60-gamma ray irradiator $(10 \mathrm{kGy})$ in extracts of dehydrated herbs, verified that irradiation did not exert any significant impact on quinic acid and other 19 phenolic compounds present.

On the other hand, shikimic acid is fundamental for plant metabolism, producing 1-phenylalanine and 1-tryptophan, which are essential amino acids for humans (Krämer et al., 2003). Furthermore, this compound is used in the synthesis of the antiviral agent oseltamivir phosphate, which is employed against the human influenza virus A and B (Marchiosi et al., 2019). Pereira et al. (2015), irradiating Ginkgo biloba (1 and $10 \mathrm{kGy}$ ) also observed that the treatment preserved compounds such as quinic and shikimic acids.

Finally, gallic acid was present in higher amounts in the control sample $\left(80.1 \mu \mathrm{g} \mathrm{g}^{-1}\right)$, with $3.8 \%$ higher amounts in the irradiated and $9.7 \%$ in the pasteurized samples, indicating the negative effect of processing on that compound. Similar results were obtained by Kumari and Khatkar (2019) when they verified a reduction in the gallic acid content after pasteurization $\left(90^{\circ} \mathrm{C}\right.$ for $\left.1 \mathrm{~min}\right)$ of aonla juice; and also by Chaikham et al. (2014) after they pasteurized longan juice $\left(90{ }^{\circ} \mathrm{C}\right.$ for $\left.2 \mathrm{~min}\right)$. The reduction in the gallic acid content in the irradiated samples of the feijoa pulp can be related to the fact that this compound has antioxidant activity, donating $\mathrm{H}$ atoms of the phenol groups to the free radicals formed during irradiation (Roidoung et al., 2016).

\section{Conclusion}

The use of different processing methods (refrigeration, pasteurization and irradiation) changed the antioxidant activity, total phenolic content and total flavonoids of feijoa pulp during the storage period, as well as the composition of phenolic compounds of this product. Pasteurization $\left(85^{\circ} \mathrm{C}\right.$ for $5 \mathrm{~min}$ ) was considered the most promising technique for the preservation of feijoa pulp during 21 days of storage $\left(5^{\circ} \mathrm{C}\right)$, since the contents of total phenolic compounds and the antioxidant activity were maintained. Conversely, for both refrigeration $\left(5^{\circ} \mathrm{C}\right)$ and irradiation $(2.0 \mathrm{kGy})$ there was a decrease in the values of these parameters during storage; however, it is worth highlighting that the flavonoid contents were more elevated. From the identification and quantification of phenolic compounds of feijoa pulp, a distinct profile difference was observed among samples subjected to different processing methods; six compounds were also quantified. The refrigerated pulps (control) presented a higher amount of gallic acid, whereas the irradi- ated demonstrated elevated levels of quinic acid and of shikimic acid, and the pasteurized sample had higher amounts of caffeic acid, ellagic acid and quercetin.

The results obtained in this research are innovative and original, since there are no reports in the literature on the identification and quantification of phenolic compounds in feijoa pulp subjected to different processing strategies (e.g. irradiation), besides the evaluation of this product regarding its antioxidant activity during storage. However, future studies should be conducted to evaluate the individual behavior of phenolic compounds during storage. Additionally, optimization of the binomial time/temperature relative to the process of pasteurization in feijoa feijoa pulp for the preservation of flavonoid compounds is necessary.

\section{Acknowledgments}

This work was supported by the São Paulo Research Foundation (FAPESP) by the grant numbers 2010/09690-1 (doctoral scholarship) and 2011/19993-4 (scientific initiation scholarship).

\section{Conflict of interest}

The authors declare that they have no conflict of interest.

\section{References}

Aherne, S.A., and O'Brien, N.M. (2002). Dietary flavonols: Chemistry, food content, and metabolism. Nutrition 18(1): 75-81.

Ahmed, M., and Eun, J.B. (2018). Flavonoids in fruits and vegetables after thermal and nonthermal processing: A review. Crit. Rev. Food. Sci. 58(18): 3159-3188.

Alov, P., Tsakovska, I., and Pajeva, I. (2015). Computational Studies of Free Radical-Scavenging Properties of Phenolic Compounds. Curr. Top. Med. Chem. 15(2): 85-104.

Aneja, K.R., Dhiman, R., Aggarwal, N.K., and Aneja, A. (2014). Emerging preservation techniques for controlling spoilage and pathogenic $\mathrm{mi}-$ croorganisms in fruit juices. Int. J. Microbiol. 2014: 758942.

Aoyama, H., Sakagami, H., and Hatano, T. (2018). Three new flavonoids, proanthocyanidin, and accompanying phenolic constituents from Feijoa sellowiana. Biosci. Biotech. Bioch. 82(1): 31-41.

Arjeh, E., Barzegar, M., and Sahari, M.A. (2015). Effects of gamma irradiation on physicochemical properties, antioxidant and microbial activities of sour cherry juice. Radiat. Phys. Chem. 114: 18-24.

Arya, A.M., Al-Obaidi, M.J., Shahid, N., Bin Noordin, M.I., Looi, C.Y., Wong, W.F., Khaing, S.L., and Mustafa, M.R. (2014). Synergistic effect of quercetin and quinic acid by alleviating structural degeneration in the liver, kidney and pancreas tissues of STZ-induced diabetic rats: A mechanistic study. Food. Chem. Toxicol. 71: 183-196.

Bhattacherjee, A.K., Tandon, D.K., Dikshit, A., and Kumar, S. (2011). Effect of pasteurization temperature on quality of aonla juice during storage. J. Food Sci. Tech. 48(3): 269-273.

Brand-Williams, W., Cuvelier, M.E., and Berset, C. (1995). Use of a free radical method to evaluate antioxidant activity. LWT-Food Sci. Technol. 28(1): 25-30

Breitfellner, F., Solar, S., and Sontag, G. (2002). Effect of gamma-irradiation on phenolic acids in strawberries. J. Food Sci. 67(2): 517-521.

Buratto, A.P., Carpes, S.T., Pereira, E.A., Diedrich, C., Oldoni, T.L.C., and da Silva, L.D. (2019). Effect of Drying Method in the Maintenance of Bioactive Compounds and Antioxidant Activity of Feijoa Pulp (Acca sellowiana). Orbital: Electron. J. Chem. 11(6): 386-393.

Castelucci, A.C.L., da Silva, P.P.M., and Spoto, M.H.F. (2020). Bioactive compounds and in vitro antioxidant activity of pulps from fruits from the Brazilian atlantic forest. Acta Sci-Technol. 42(1): e44503.

Castro-Lopez, C., Sanchez-Alejo, E.J., Saucedo-Pompa, S.R., Rojas, R., 
Aranda-Ruiz, J., and Martinez-Avila, G.C.G. (2016). Fluctuations in phenolic content, ascorbic acid and total carotenoids and antioxidant activity of fruit beverages during storage. Heliyon 2(9): e00152.

Chaikham, P., Apichartsrangkoon, A., and Seesuriyachan, P. (2014). Physical and biochemical qualities of pressurized and pasteurized longanjuices upon storage. Emir. J. Food Agr. 26(3): 218-228.

Cinkilic, N., Cetintas, S.K., Zorlu, T., Vatan, O., Yilmaz, D., Cavas, T., Tunc, S., Ozkan, L., and Bilaloglu, R. (2013). Radioprotection by two phenolic compounds: Chlorogenic and quinic acid, on X-ray induced DNA damage in human blood lymphocytes in vitro. Food Chem. Toxicol. 53: 359-363.

Crozier, A. (2003). Classification and Biosynthesis of Secondary Plant Products: An Overview. In: Goldberg, G. (Ed.). Plants: Diet and Health. John Wiley \& Sons, Ltd, pp. 27-48.

Dastmalchi, K., Flores, G., Petrova, V., Pedraza-Peñalosa, P., and Kennelly, E.J. (2011). Edible Neotropical Blueberries: Antioxidant and Compositional Fingerprint Analysis. J. Agric. Food Chem. 59(7): 3020-3026.

Fuleki, T., and Ricardo-Da-Silva, J.M. (2003). Effects of cultivar and processing method on the contents of catechins and procyanidins in grape juice. J. Agric. Food Chem. 51(3): 640-646.

Galani, J.H.Y., Patel, J.S., Patel, N.J., and Talati, J.G. (2017). Storage of fruits and vegetables in refrigerator increases their phenolic acids but decreases the total phenolics, anthocyanins and vitamin $C$ with subsequent loss of their antioxidant capacity. Antioxidants 6(3): 59.

Gil-Izquierdo, A., Gil, M.I., and Ferreres, F. (2002). Effect of processing techniques at industrial scale on orange juice antioxidant and beneficial health compounds. J. Agric. Food Chem. 50(18): 5107-5114.

Guiné, R.D.P.F., and Barroca, M.J. (2014). Influence of processing and storage on fruit juices phenolic compounds. Int. J. Med. Biol. Front. 20(1): 45

Hadwiger, L.A., and Schwochau, M.E. (1971). Ultraviolet light-induced formation of pisatin and phenylalanine ammonia lyase. Plant Physiol. 47(4): 588.

Hajar, H.R., Mouhib, M., Nabloussi, A., Kzaiber, F., Latrache, H., and Hanine, H. (2019). Effect of different doses of gamma irradiation on biochemical and microbiological properties of sesame (Sesamum indicum L.) seeds. Mor. J. Chem. 7(3): 538-547.

Hung, T.M., Na, M., Thuong, P.T., Su, N.D., Sok, D., Song, K.S., Seong, Y.H., and Bae, K. (2006). Antioxidant activity of caffeoyl quinic acid derivatives from the roots of Dipsacus asper Wall. J. Ethnopharmacol. 108(2): 188-192.

Ielpo, M.T., Basile, A., Miranda, R., Moscatiello, V., Nappo, C., Sorbo, S. Laghi, E., Ricciardi, M.M., Ricciardi, L., and Vuotto, M.L. (2000). Immunopharmacological properties of flavonoids. Fitoterapia. 71(1) S101-S109.

Igual, M., Garcia-Martinez, E., Camacho, M.M., and Martinez-Navarrete, N. (2011). Changes in flavonoid content of grapefruit juice caused by thermal treatment and storage. Innov. Food Sci. Emerg. Technol. 12(2): 153-162.

Jo, Y., Ameer, K., Chung, N., and Kwon, J.H. (2019). Influence of gamma irradiation on volatile flavour profiles and physicochemical attributes of navel oranges (Citrus sinensis L.) under post-irradiation storage. Int. Food Res. J. 26(3): 1035-1043.

Karami, M., Saeidnia, S., and Nosrati, A. (2013). Study of the hepatoprotective activity of methanolic extract of Feijoa sellowiana fruits against MDMA using the isolated Rat Liver Perfusion System. Iran. J. Pharm. Res. 12(1): 85-91.

Karwowski, M., Masson, M., Lenzi, M., Scheer, A., and Haminiuk, C. (2013). Characterization of tropical fruits: rheology, stability and phenolic compounds. Acta Aliment. 42(4): 586-598.

Kaur, C., and Kapoor, H.C. (2001). Antioxidants in fruits and vegetables the millennium's health. Int. J. Food Sci. Tech. 36(7): 703-725.

Khan, M.K., Ahmad, K., Hassan, S., Imran, M., Ahmad, N., and Xu, C.M. (2018). Effect of novel technologies on polyphenols during food processing. Innov. Food Sci. Emerg. Technol. 45: 361-381.

Krämer, M., Bongaerts, J., Bovenberg, R., Kremer, S., Müller, U., Orf, S., Wubbolts, M., and Raeven, L. (2003). Metabolic engineering for microbial production of shikimic acid. Metab. Eng. 5(4): 277-283.

Kumari, P., and Khatkar, B.S. (2019). Effect of processing treatment on nutritional properties and phytochemical contents of aonla (Emblica officinalis) juice. J. Food Sci. Tech. MYS 56(4): 2010-2015.
Kuskoski, E.M., Asuero, A.G., Troncoso, A.M., Mancini-Filho, J., and Fett, R. (2005). Aplicación de diversos métodos químicos para determina actividad antioxidante en pulpa de frutos. Food Sci. Technol. (Campinas) 25(4): 726-732.

Lee, J., Kim, J., Srinivasan, P., Choi, J., Kim, J., Han, S.D., and Byun, M. (2009). Effect of gamma irradiation on microbial analysis, antioxidant activity, sugar content and color of ready-to-use tamarind juice during storage. LWT-Food Sci. Technol. 42(1): 101-105.

Magnani, C., Isaac, V., Corrêa, M., and Salgado, H. (2014). Caffeic acid: A review of its potential use in medications and cosmetics. Anal. Methods 6: 3203.

Marchiosi, R., Ferro, A.P., Ramos, A.V.G., Baldoqui, D.C., Constantin, R.P., Constantin, R.P., dos Santos, W.D., and Ferrarese-Filho, O. (2019). Ca lophyllum brasiliense Cambess: an alternative and promising source of shikimic acid. Sustain. Chem. Pharm. 14: 100188.

Marszałek, K., Mitek, M., and Skąpska, S. (2015). The effect of thermal pasteurization and high pressure processing at cold and mild temperatures on the chemical composition, microbial and enzyme activ ity in strawberry purée. Innov. Food Sci. Emerg. Technol. 27: 48-56.

Medina-Meza, I.G., and Barbosa-Canovas, G.V. (2015). Assisted extraction of bioactive compounds from plum and grape peels by ultrasonics and pulsed electric fields. J. Food Eng. 166: 268-275.

Mena, P., Vegara, S., Martí, N., García-Viguera, C., Saura, D., and Valero, M. (2013). Changes on indigenous microbiota, colour, bioactive compounds and antioxidant activity of pasteurised pomegranate juice. Food Chem. 141(3): 2122-2129.

Mosbah, H., Chahdoura, H., Adouni, K., Kamoun, J., Boujbiha, M.A., Gonzalez-Paramas, A.M., Santos-Buelga, C., Ciudad-Mulero, M., Morales, P., Fernandez-Ruiz, V., Achour, L., and Selmi, B. (2019). Nutritional properties, identification of phenolic compounds, and enzyme inhibitory activities of Feijoa sellowiana leaves. J. Food Biochem. 43(11): e13012.

Nagy, T.O., Solar, S., Sontag, G., and Koenig, J. (2011). Identification of phenolic components in dried spices and influence of irradiation. Food Chem. 128(2): 530-534.

Oufedjikh, H., Mahrouz, M., Amiot, M.J., and Lacroix, M. (2000). Effect of $\gamma$-irradiation on phenolic compounds and phenylalanine ammonialyase activity during storage in relation to peel injury from peel of Citrus clementina Hort. Ex. Tanaka. J. Agric. Food Chem. 48(2): 559-565.

Park, Y.K., Koo, M.H., Sato, H.H., and Contado, J.L. (1995). Estudo de alguns componentes da própolis coletada por Apis mellifera no Brasil. Arq. biol. tecnol. 38(4): 1235-1259.

Pereira, E., Barros, L., Antonio, A., Bento, A., and Ferreira, I.C.F.R. (2015) Analytical methods applied to assess the effects of gamma irradiation on color, chemical composition and antioxidant activity of Ginkgo biloba L. Food Anal. Methods 8(1): 154-163.

Rockenbach, I.I., Rodrigues, E., Cataneo, C., Gonzaga, L.V., Lima, A., Mancini-filho, J., and Fett, R. (2008). Phenolic acids and antioxidant activity of Physalis peruviana L. fruit. Brazilian Journal of Food and Nutrition 19(3): 271-276.

Roidoung, S., Dolan, K.D., and Siddiq, M. (2016). Gallic acid as a protective antioxidant against anthocyanin degradation and color loss in vitamin-C fortified cranberry juice. Food Chem. 210: 422-427.

Romero Rodriguez, M.A., Vazquez Oderiz, M.L., Lopez Hernandez, J., and Lozano, J.S. (1992). Determination of Vitamin C and organic acids in various fruits by HPLC. J. Chromatogr. Sci. 30(11): 433-437.

Rufino, M.D.S.M., Alves, R.E., Brito, E.S.D., Morais, S.M.D., Sampaio, C.G., Pérez-Jiménez, J., and Saura-Calixto, F.D. (2007). Metodologia Científica: Determinaão da atividade antioxidante total em frutas pela captura do radical ABTS+. Embrapa Agroindústria Tropical. Comunicado Técnico 127:

Shahidi, F. (2005). Nutraceuticals and Functional Foods in Health Promotion and Disease Risk Reduction. Acta Hortic. 680: 13-24.

Silva, P.P.M., Martin, J.G.P., and Spoto, M.H.F. (2018). Effect of gamma radiation and pasteurization on the shelf-life of juçara pulp (Euterpe edulis). AcAg 67(4): 471-478.

Singleton, V.L., and Rossi, J.A. (1965). Colorimetry of total phenolics with phosphomolybdic-phosphotungstic acid reagents. Am. J. Enol. Vitic. Sciences(3): 144-158.

Song, H.-P., Kim, D.-H., Jo, C., Lee, C.-H., Kim, K.-S., and Byun, M.-W. (2006) Effect of gamma irradiation on the microbiological quality and an- 
tioxidant activity of fresh vegetable juice. Food Microbiol. 23(4): 372-378.

Szymanowska, U., and Baraniak, B. (2019). Antioxidant and Potentially Anti-Inflammatory Activity of Anthocyanin Fractions from Pomace Obtained from Enzymatically Treated Raspberries. Antioxidants (Basel) 8(8): 299.

Tuncel, N.B., and Yilmaz, N. (2015). Optimizing the extraction of phenolics and antioxidants from feijoa (Feijoa sellowiana, Myrtaceae). J. Food Sci. Tech. MYS. 52(1): 141-150.

Wani, M.R., Singh, S.S., and Sharma, V. (2019). Biochemical composition and photosynthetic activity of Pongamia pinnata (L.) Pierre in response to acute Co-60 gamma-irradiation. J. For. Res. 30(4): 12211231.

Weston, R.J. (2010). Bioactive products from fruit of the feijoa (Feijoa sell- owiana, Myrtaceae): A review. Food Chem. 121(4): 923-926.

Yokoyama, A., Sakakibara, H., Crozier, A., Kawai, Y., Matsui, A., Terao, J., Kumazawa, S., and Shimoi, K. (2009). Quercetin metabolites and protection against peroxynitrite-induced oxidative hepatic injury in rats. Free Radic. Res. 43(10): 913-921.

Yousef, M.I., Omar, S.A.M., El-Guendi, M.I., and Abdelmegid, L.A. (2010). Potential protective effects of quercetin and curcumin on paracetamol-induced histological changes, oxidative stress, impaired liver and kidney functions and haematotoxicity in rat. Food Chem. Toxicol 48(11): 3246-3261.

Zafrilla, P., Ferreres, F., and Tomás-Barberán, F.A. (2001). Effect of processing and storage on the antioxidant ellagic acid derivatives and flavonoids of red raspberry (Rubus idaeus) jams. J. Agric. Food Chem. 49(8): 3651-3655. 